\title{
Uso do Moodle como estímulo aos estudos extraclasse no Ensino Fundamental: Uma experiência com o $5^{\circ}$ Ano
}

\author{
Marcia Regina Kaminski ${ }^{1}$, Clodis Boscarioli ${ }^{2}$ \\ ${ }^{1}$ Escola Municipal Aloys João Mann - Rua Salgado Filho, 3533 - Bairro Cancelli, CEP \\ 85811-100 - Cascavel - PR - Brasil \\ ${ }^{2}$ Universidade Estadual do Oeste do Paraná - UNIOESTE. Rua Universitária, 2069 - \\ Bairro Faculdade, CEP: 85819-110 - Cascavel - PR - Brasil \\ marciarkjf@gmail.com, clodis.boscarioli@unioeste.br
}

\begin{abstract}
The integration of technologies in the teaching and learning processes has been assuming an important role in education, especially in the early years of Elementary Education, given the potential contribution of its use. Considering this importance and the need to cultivate Afterschool study habits, this work brings a report of an experience in the use of Moodle platform by students of the 5th year of Elementary Education as a stimulus to study habits, developing the autonomy of students and collaborating on improving their performance.
\end{abstract}

Resumo. A integração de tecnologias nos processos de ensino-aprendizagem vem assumindo relevante papel na educação, com destaque nos anos iniciais do Ensino Fundamental, dado o potencial de contribuição da sua utilização. Considerando esta importância e a necessidade de cultivar hábitos de estudos extraclasses, este trabalho traz o relato de uma experiência do uso da Plataforma Moodle pelos alunos do $5^{\circ}$ Ano do Ensino Fundamental como estímulo aos hábitos de estudo, desenvolvendo a autonomia dos estudantes $e$ colaborando na melhora de seu desempenho.

\section{Introdução}

A escola atual precisa reconhecer as mudanças que acompanham o perfil de seus alunos e buscar estratégias que sejam favoráveis à aprendizagem. Não se pode mais negar que a tecnologia faz parte da vida dos alunos. Cada vez mais eles estão em contato com tecnologias digitais atuais, seja por meio da escola como em seu cotidiano fora dela.

O uso de Tecnologias da Informação e da Comunicação (TIC) vem contribuindo com o processo de ensino-aprendizagem, seja pelo uso de jogos educacionais, redes sociais entre outros em sala de aula, como pelas novas possibilidades que tem emergido a partir da utilização de Ambientes Virtuais de Aprendizagem (AVA) como a Plataforma Moodle no apoio ao ensino presencial, configurando práticas pedagógicas alternativas que proporcionam o desenvolvimento da criatividade e da autonomia dos alunos, dentre outras habilidades. A escola pode ajudar os alunos a perceberem o valor prático, científico, histórico e social da tecnologia, e estas não apenas podem ser úteis como metodologia de ensino presencial, mas para resolução de atividades extraclasse.

Perante observações do contexto escolar percebe-se uma dificuldade constantemente levantada pelos professores, a de que os alunos não possuem hábitos de 
estudo extraclasses, uma vez que muitos não realizam as tarefas de casa solicitadas pelos professores. Neste sentido, é relevante o uso das TIC como recursos de estímulo ao desenvolvimento das lições de casa.

As tarefas ou lições de casa podem ser definidas como atividades que são repassadas aos alunos para serem cumpridas fora do horário em que frequentam o ensino regular. Um dos seus principais objetivos é incentivar o hábito de estudo, desenvolver a responsabilidade do aluno, além de auxiliar na aprendizagem e fixação dos conteúdos abordados em sala de aula.

A Plataforma Moodle é um dos recursos tecnológicos que podem motivar os alunos a terem hábitos mais regulares de estudo, pois segundo Santos (2014) proporciona uma aprendizagem interativa através de recursos familiares aos estudantes como chats, fóruns e outros que já utilizam em comunidades virtuais. Alunos e professores podem fazer uso deste instrumento almejando um aumento no interesse pelo estudo, visando à melhoria do processo ensino-aprendizagem.

Este artigo traz a experiência de uso da Plataforma Moodle com o objetivo de analisar suas contribuições ao processo de ensino-aprendizagem em turmas do $5^{\circ}$ ano do Ensino Fundamental, com foco em atividades extraclasse e está organizado como segue: A Seção 2 discute a importância das atividades extraclasses e discute como as tecnologias podem ser utilizadas nesse contexto; Na Seção 3 a experiência realizada com Moodle é descrita; A Seção 4 discute os resultados obtidos nos anos de aplicação desse projeto e, por fim, na Seção 5 estão as conclusões e perspectivas desse trabalho.

\section{Atividades extraclasse mediadas por tecnologias}

As tarefas de casa tem importante papel no desempenho escolar. Criar hábitos de estudo extraclasse melhora o rendimento escolar. Nesse sentido, Dewey (1979, p.167) coloca que o objetivo ou o fim da educação é formar hábitos mentais, especialmente o hábito "de aprender a aprender". Dessa forma, a escola deve propiciar condições para o indivíduo desenvolver continuamente hábitos intelectuais. Dewey na sua concepção do método de ensinar e aprender enfatiza que os métodos devem priorizar as condições que estimulem, promovam e coloquem "em prova" a reflexão e o pensamento.

O estudo extraclasse é importante para consolidação do processo de aprendizagem. Nesta perspectiva, Davídov e Márkova (1987) colocam que de fato a atividade de estudo oferece a possibilidade de transformações internas e, como consequência, o desenvolvimento dos estudantes. Entre as funções da lição de casa, podem ser mencionados a sistematização do aprendizado escolar, aprofundamento dos conceitos aprendidos e preparação para novos conteúdos. Para Libâneo (1994, p.192), a tarefa de casa "é um importante complemento didático para a consolidação, estreitamente ligado ao desenvolvimento das aulas".

As lições de casa também servem de parâmetro para orientar o trabalho do professor. Por analisar as atividades feitas pelos alunos sozinhos em casa, o professor tem a possibilidade de verificar quais são as dúvidas individuais ou coletivas, retomando pontos nos quais os alunos apresentaram dificuldades. Nesta perspectiva, a Lei de Diretrizes e Bases da Educação Nacional - LDB 9394/96 em seu artigo 24, inciso $\mathrm{V}$, referencia como deve ser o processo de avaliação pelos professores:

V. a verificação do rendimento escolar observará os seguintes critérios: a) avaliação contínua e cumulativa do desempenho do aluno, com prevalência 
V Congresso Brasileiro de Informática na Educação (CBIE 2016)

Anais do XXII Workshop de Informática na Escola (WIE 2016)

dos aspectos qualitativos sobre os quantitativos e dos resultados ao longo do período sobre os de eventuais provas finais; b) possibilidade de aceleração de estudos para os alunos com atraso escolar; c) possibilidade de avanço nos cursos e nas séries, mediante verificação do aprendizado (p. 14-15).

Ainda sobre a educação básica, a LDB 9394/96 delibera que a avaliação deve ser compreendida como um processo contínuo e cumulativo objetivando detectar problemas e servir como diagnóstico. Deve ser considerada como um processo em constante transformação, visando superação das dificuldades do processo de ensinoaprendizagem, sendo as tarefas de casa uma valiosa aliada do professor.

Observa-se, no entanto, que os alunos, de modo geral, não se sentem muito motivados a estudar fora do horário de ensino regular. Como motivar os alunos a desenvolverem hábitos de estudo através da realização de tarefas de casa?

Por ser uma prática antiga, torna-se às vezes permeada de pouca reflexão, pouco pensada na sua forma em si. Analisar as lições de casa em um contexto atual, permeado pelas tecnologias, pode ter significativa contribuição. Com o avanço da internet, o acesso rápido às informações modifica a forma como os estudantes encaram o aprendizado escolar e como realizam as tarefas de casa. É importante buscar recursos que sejam aliados ao processo de ensino-aprendizagem e alternativas atuais à aplicação das lições de casa que ajudem os alunos a perceberem a importância destas para o seu desenvolvimento e os motivem a executá-las. Entre essas alternativas estão as redes sociais, como descrevem Rodrigues e Elia (2013) e os AVA como aqui considerados.

Tavares (2009, p. 5) define um AVA como "um ambiente criado na internet, através do uso de diferentes recursos tecnológicos, reunidos a fim de criar um contexto educacional que possibilita diferentes tipos de interação entre alunos, professores e conteúdo". Este tipo de ambiente interativo e flexível promove a conexão das pessoas, o debate, o compartilhamento de informações, o desenvolvimento da autonomia dos alunos em pesquisar os assuntos propostos e buscarem novas informações.

O Moodle é um AVA que tem ocupado espaço considerável na educação por permitir que conteúdos e materiais sejam sistematizados para que os alunos façam suas pesquisas, organizem seus hábitos de estudos, resolvam atividades propostas pelo professor, e depois compartilhem suas opiniões e conclusões com a turma e com o professor. O objetivo é promover o aprendizado baseando-se na pedagogia sócio construtivista. Para Dougiamas e Taylor (2000, p. 3), "o Moodle trata a aprendizagem como uma atividade social. É um software que está baseado no construtivismo social”.

O Moodle permite a utilização de vários recursos interativos como vídeos, áudios, jogos, enquetes, fóruns, questões de múltipla escolha, dissertativas, quadros de avisos, chats, além de interação com o professor que pode corrigir as atividades de forma online e dar o retorno aos alunos por meio de mensagens enviadas pela própria plataforma. Ao final de cada tentativa o aluno tem o feedback das questões que estão certas ou erradas, e tem a oportunidade de refazer a atividade, fazendo novas pesquisas, corrigindo os erros observados. É importante não apenas inserir os recursos e atividades na plataforma, mas estimular os alunos a pesquisarem e interagirem com o grupo.

As possibilidades disponíveis no ambiente Moodle são diversas, e embora bastante utilizado em cursos de Educação a Distância, Formação de Professores e Cursos de Graduação, pode-se utilizá-lo também como ferramenta complementar ao trabalho do professor no Ensino Fundamental, a exemplo do relato de Santos (2014) 
sobre o uso do Moodle no $6^{\circ}$ e $7^{\circ}$ anos do Ensino Fundamental na disciplina de Ciências, onde havia a apresentação do conteúdo em sala de aula e nas aulas de informática atividades eram desenvolvidas no Moodle de forma complementar.

Experiências de uso do Moodle no desenvolvimento de atividades extraclasse também são relatadas. Karas e Santos (2008) utilizaram o Moodle no apoio ao ensino de Ciências com alunos de $8^{\circ}$ série do Ensino Fundamental. Neste trabalho foi criado um módulo de apoio para abordagem de um conteúdo específico. Assemany et al. (2010) também apresentam uma experiência do uso de Moodle no ensino de Matemática na Educação Básica com alunos do $8^{\circ}$ ano do Ensino Fundamental, no qual foi elaborado um ambiente colaborativo de apoio ao ensino, composto basicamente por dois recursos: um curso online sob a supervisão do professor da turma com links e referências de material de apoio dos conteúdos, e um fórum de dúvidas para resolução dos exercícios. O trabalho ora relatado se diferencia dos demais por estar centrado em alunos dos anos iniciais do Ensino Fundamental, mais especificamente, no $5^{\circ}$ ano.

\section{Métodos: Usando o Moodle no $5^{\circ}$ ano do Ensino Fundamental}

A experiência relatada acontece na Escola Municipal Aloys João Mann, da Rede Pública Municipal de Ensino da cidade de Cascavel - PR. Trata-se de uma escola de porte médio que atende atualmente trezentos e vinte e um alunos entre a Educação Infantil e Anos Iniciais do Ensino Fundamental. A escola está localizada na região central do município, onde a população é considerada de classe média baixa.

Dentro das atividades desenvolvidas no período regular de aula, todas as turmas, incluindo as de Educação Infantil, contam com atendimento semanal de uma hora e vinte minutos no Laboratório de Informática Educacional. As aulas, planejadas em conjunto com o professor regente, são ministradas por uma Instrutora de Informática Educacional com qualificação técnica e pedagógica para este trabalho. Os conteúdos abordados estão em conformidade com o Currículo para a Rede Pública do município e também com o trabalho realizado pelo professor regente de cada turma.

O foco destas aulas é trabalhar o conteúdo pedagógico curricular utilizando os recursos tecnológicos como ferramentas de apoio ao ensino. Dentro dos projetos desenvolvidos nestas aulas, estão o Ensino de Programação na Infância, a Robótica Educacional e o uso da Plataforma Moodle em atividades extraclasse, foco desse artigo.

Em 2013 surgiu a ideia de implantar na escola uma plataforma de estudo online a ser utilizada pelos alunos como apoio ao ensino presencial. A proposta era que os alunos utilizassem-na para realização de atividades extraclasse acompanhadas e avaliadas pela professora regente da turma, pela instrutora de informática e pela coordenação pedagógica da escola. Com o apoio da Coordenação e Direção da Escola o projeto começou neste mesmo ano com as duas turmas de $5^{\circ}$ ano.

O Moodle foi adotado e instalado no servidor da Escola conforme instruções de Claro (2009), uma vez que nele os professores poderiam realizar o acompanhamento dos trabalhos, corrigir e tornar o processo de estudo extraclasse mais interativo por meio de áudios, vídeos, chats, fóruns e outros recursos disponíveis. Foi hospedado no site da escola já conhecido pelos alunos por ser constantemente utilizado nas aulas de informática. No link alunos é possível visualizar as atividades de cada turma. Um link denominado para casa foi criado, que direciona para o Moodle da escola. 
V Congresso Brasileiro de Informática na Educação (CBIE 2016)

Anais do XXII Workshop de Informática na Escola (WIE 2016)

Após a instalação e a hospedagem no site da escola, foi preciso cadastrar os usuários (alunos e professores das turmas de $5^{\circ}$ ano, bem como o administrador do sistema). Cada usuário recebeu um login e uma senha. Todos estes passos foram executados pela Instrutora de Informática da Escola. Depois disso iniciou-se o processo de inserção das atividades no sistema. Os professores regentes repassaram os conteúdos e os modelos das atividades que desejavam enviar como tarefas. A instrutora de informática inseriu estas atividades na plataforma fazendo as adaptações necessárias.

Antes do envio das lições de casa pelo Moodle foi preciso preparar os alunos, em algumas aulas de informática, para utilizar o ambiente. Na sequência, foi lhes dito que a partir de então seriam enviadas tarefas para serem realizadas em casa pela plataforma. Surgiu um impasse: nem todos os alunos possuíam em casa um computador com acesso à internet. A solução foi disponibilizar no laboratório de informática da escola um horário em contraturno, para que estes alunos pudessem realizar a atividade proposta. Foi preciso fixar um horário no cronograma de atendimento do laboratório, e solicitar a autorização dos pais para que os alunos viessem em contra turno na escola.

Desde então essa sistemática é adotada, ano a ano, nas turmas do $5^{\circ}$ ano. Semanalmente é cadastrada na plataforma uma nova tarefa, sempre em consonância ao conteúdo abordado em sala de aula pelo professor regente da turma. É possível elaborar atividades de completar, múltipla escolha, respostas, relacionar, jogos, entre outros modelos, bem como inserir vídeos sobre o conteúdo abordado para que os alunos assistam e depois comentem ou resolvam os exercícios.

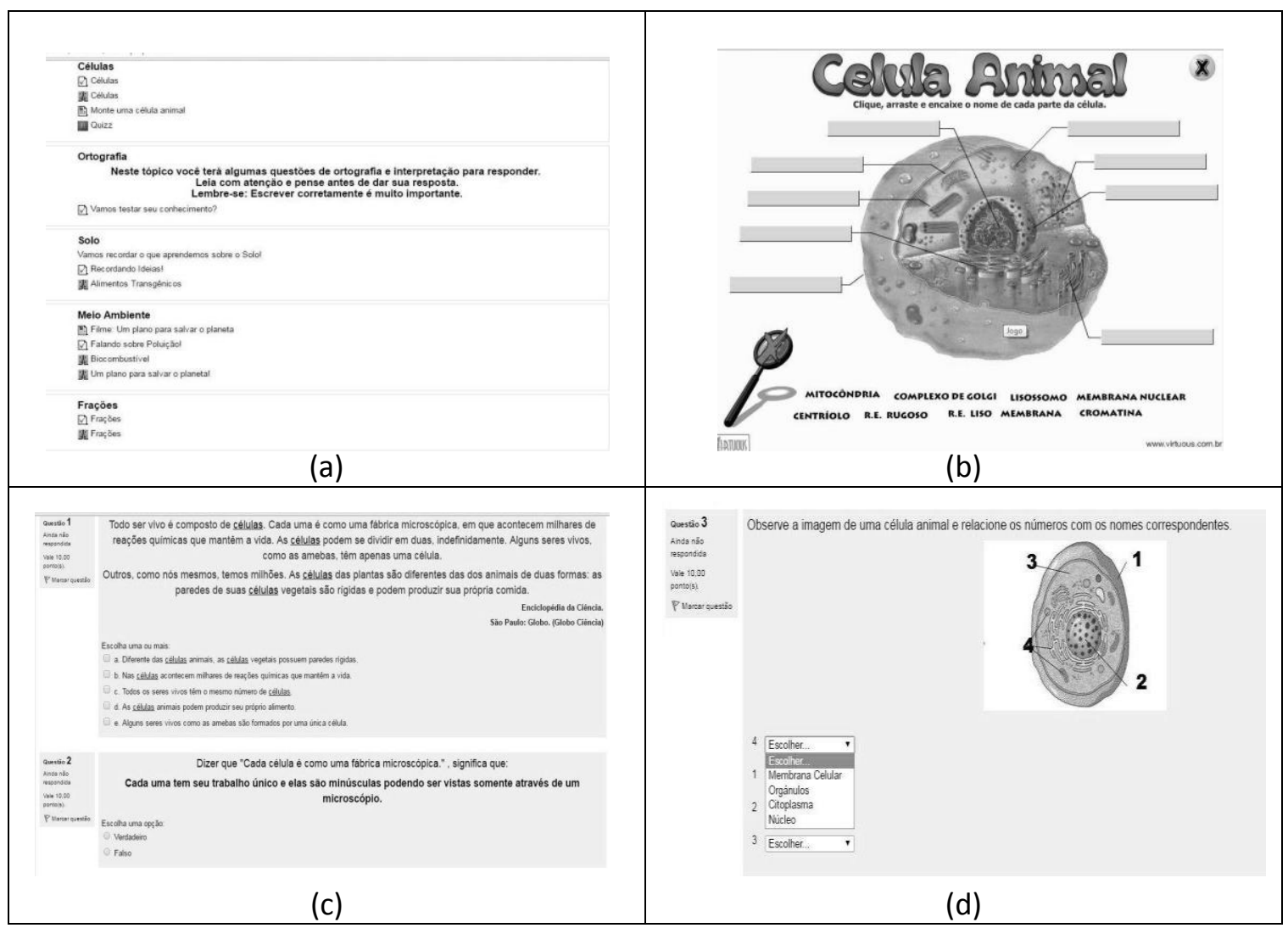

Figura 1. Exemplos de atividades extraclasse inseridas no Moodle

A Figura 1 exemplifica uma das atividades extraclasse inseridas no Moodle, na visão dos alunos. Na Figura 1(a) está a tela inicial na visão dos alunos, de acesso às 
V Congresso Brasileiro de Informática na Educação (CBIE 2016)

Anais do XXII Workshop de Informática na Escola (WIE 2016)

atividades. As Figuras 1(b)-(d) ilustram diferentes atividades sobre a disciplina de Ciências, com conteúdos e formas diferentes de interação.

A Tabela 1 traz exemplos da sistematização dos trabalhos desenvolvidos em sala de aula e sua complementação com atividades extraclasse no Moodle.

Tabela 1. Sistematização das atividades em sala de aula e no Moodle

\begin{tabular}{|c|c|c|c|}
\hline $\begin{array}{c}\text { Área do } \\
\text { Conhecimento }\end{array}$ & Conteúdos & $\begin{array}{c}\text { Atividades com o professor } \\
\text { regente } \\
\end{array}$ & Atividades extraclasse no Moodle \\
\hline \multirow[b]{2}{*}{ Geografia } & $\begin{array}{l}\text { Continentes } \\
\text { Oceanos } \\
\text { Hemisférios }\end{array}$ & $\begin{array}{l}\text { Trabalhos com mapas, livro } \\
\text { didático e globo terrestre. }\end{array}$ & $\begin{array}{l}\text { Questionário a ser respondido com base } \\
\text { em sites indicados; Jogos de montagem e } \\
\text { pintura de mapas; Quiz. }\end{array}$ \\
\hline & $\begin{array}{l}\text { Regiões } \\
\text { Brasileiras }\end{array}$ & $\begin{array}{l}\text { Trabalhos com mapas e livro } \\
\text { didático. }\end{array}$ & $\begin{array}{l}\text { Vídeos abordando aspectos geográficos, } \\
\text { históricos e culturais de cada região } \\
\text { brasileira. } \\
\text { Questionário a ser respondido com auxílio } \\
\text { de pesquisas em sites indicados. } \\
\text { Jogos de montagem e pintura de mapas. } \\
\text { Atividade de associação entre estados e } \\
\text { capitais do Brasil. }\end{array}$ \\
\hline \multirow[t]{2}{*}{ Ciências } & $\begin{array}{l}\text { Meio Ambiente } \\
\text { Solo } \\
\text { Alimentação } \\
\text { Saudável } \\
\text { Água: } \\
\text { - estados físicos } \\
\text { - uso adequado } \\
\text { - preservação }\end{array}$ & 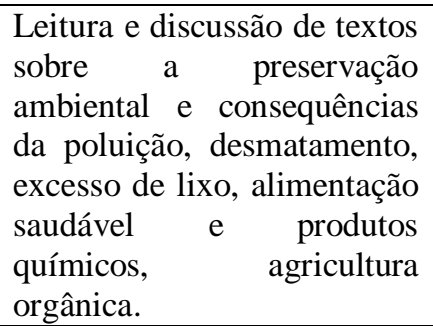 & $\begin{array}{l}\text { Vídeos relacionados aos temas e abertura } \\
\text { de fóruns para discussão. } \\
\text { Questionário - incluindo atividades de } \\
\text { completar, associação, correspondência, } \\
\text { verdadeiro ou falso, etc. - sobre os } \\
\text { aspectos teóricos de cada tema. } \\
\text { Jogos e desafios sobre as temáticas. }\end{array}$ \\
\hline & Células & $\begin{array}{l}\text { Abordagem teórica com } \\
\text { base no livro didático. }\end{array}$ & $\begin{array}{l}\text { Vídeo e questionário sobre o tema. } \\
\text { Aplicação de jogos. }\end{array}$ \\
\hline Matemática & Frações & $\begin{array}{l}\text { Abordagem dos aspectos } \\
\text { teóricos do conteúdo por } \\
\text { exposição oral, exercícios do } \\
\text { livro didático e outras } \\
\text { fontes. }\end{array}$ & $\begin{array}{l}\text { Vídeos explicativos relacionados ao } \\
\text { conteúdo como forma de revisão e tira } \\
\text { dúvidas. } \\
\text { Questionário - incluindo atividades de } \\
\text { completar, associação, correspondência, } \\
\text { verdadeiro ou falso, etc., e Jogos. }\end{array}$ \\
\hline $\begin{array}{l}\text { Língua } \\
\text { Portuguesa }\end{array}$ & $\begin{array}{l}\text { Ortografia, } \\
\text { leitura } \\
\text { interpretação } \\
\text { textual }\end{array}$ & $\begin{array}{l}\text { Explicação de conteúdos via } \\
\text { exposição oral e atividades } \\
\text { de leitura, interpretação e } \\
\text { escrita do livro didático e } \\
\text { outras fontes. }\end{array}$ & $\begin{array}{l}\text { Questionários - incluindo atividades de } \\
\text { completar, associação, correspondência, } \\
\text { verdadeiro ou falso, etc. Quiz, Jogos. } \\
\text { A leitura, interpretação e produção são } \\
\text { conteúdos abordados de forma } \\
\text { interdisciplinar em todas as atividades. }\end{array}$ \\
\hline \multirow[b]{2}{*}{ História } & $\begin{array}{l}\text { Colonização } \\
\text { Brasileira }\end{array}$ & $\begin{array}{l}\text { Leitura e discussão de textos } \\
\text { relacionados ao tema e } \\
\text { explicação do professor. }\end{array}$ & $\begin{array}{l}\text { Vídeos e questionário a ser respondido } \\
\text { por meio de pesquisa sobre o tema. }\end{array}$ \\
\hline & $\begin{array}{l}\text { História de } \\
\text { Cascavel e do } \\
\text { bairro da escola }\end{array}$ & $\begin{array}{l}\text { Leitura e discussão de textos } \\
\text { relacionados ao tema e } \\
\text { explicação do professor. }\end{array}$ & $\begin{array}{l}\text { Questionário sobre aspectos históricos e } \\
\text { geográficos do município e do bairro da } \\
\text { escola a ser respondido com base em sites } \\
\text { direcionados e com o auxílio dos } \\
\text { responsáveis. }\end{array}$ \\
\hline
\end{tabular}

Os alunos tem o prazo de uma semana para assistirem aos vídeos, comentarem nos fóruns e resolverem as atividades. Cada atividade pode ser resolvida até três vezes para obter pontuação maior. Ao término de cada tentativa o aluno recebe um feedback com o resultado dos seus erros e acertos. Para impedir que fiquem adivinhando as respostas, foi usado um recurso de descontar pontos caso a resposta esteja errada. 
V Congresso Brasileiro de Informática na Educação (CBIE 2016)

Anais do XXII Workshop de Informática na Escola (WIE 2016)

Assim, o aluno é estimulado a pensar, ler e raciocinar antes de clicar na resposta. Os professores podem acompanhar o relatório de quantos alunos fizeram as atividades, quem comentou nos fóruns, ver a pontuação, bem como enviar mensagens individuais ou à turma.

\section{Resultados e Discussão}

O uso do Moodle em lições de casa está no quarto ano consecutivo. A cada ano novas turmas são cadastradas e o trabalho reiniciado. Em 2013 foram 53 alunos usuários do Moodle, 58 em 2014, 56 em 2015, e atualmente 53, totalizando 220 alunos no projeto.

Interessante notar que os alunos que não têm acesso à internet em suas residências demonstram um esforço especial em desenvolver os trabalhos propostos, fazendo uso dos horários disponibilizados para eles no laboratório de informática da escola. A necessidade do deslocamento em contra turno escolar para fazer a lição de casa não é encarada como algo dificultoso ou ruim, mas como oportunidade para realizar os exercícios. Vale destacar que, com a finalidade de manter o caráter de lição de casa das atividades do Moodle, que devem ser desenvolvidas pela criança, enquanto estão no laboratório realizando suas lições não recebem auxílio.

Dado que o objetivo do projeto é utilizar as atividades como complemento ao trabalho do professor, no formato de lição de casa, é essencial que esses exercícios estejam de acordo com o conteúdo abordado em sala de aula. Desta forma, a comunicação entre os professores regentes e a instrutora de informática, responsável pelo Moodle é fundamental. Semanalmente é preciso contato com os professores para que repassem as informações dos conteúdos abordados, de que forma e em quais níveis de complexidade, para que as atividades como lição de casa sejam possíveis de serem cumpridas pelos alunos. Além disso, é importante que o professor regente direcione a criação das atividades e as avalie antes de serem liberadas aos estudantes.

Para averiguar como o projeto tem ajudado no processo ensino-aprendizagem, foi realizada uma pesquisa com os professores regentes. A abordagem foi a de pesquisa qualitativa e um questionário com perguntas abertas sobre o andamento e contribuições do projeto foi usado como instrumento de coleta de dados encaminhado aos seis professores, que atuam ou atuaram como regentes das turmas de $5^{\circ}$ Ano da escola desde o início da implantação do projeto e que, portanto, acompanharam o seu desenvolvimento. Na sistematização dos dados foi realizada a codificação das respostas sendo as falas dos professores nomeadas de "P" seguidas de sequência numérica.

Inicialmente os professores foram questionados sobre a importância dos estudos extraclasse no processo de ensino-aprendizagem. Algumas respostas seguem transcritas:

"Considero que os estudos extraclasse são de grande relevância para que o estudante, assim como os pais, compreendam que a rotina de estudos não acaba na porta da escola, após o período determinado para estudo sistematizado em uma instituição de ensino. Em casa, o estudo deve continuar, sob a forma de tarefa de casa, desenvolvendo no estudante uma rotina de estudos extraclasses". (P1)

"A tarefa de casa é fundamental no processo de aprendizagem, pois ao elaborar as atividades que serão enviadas para casa, já é pensado numa forma de revisar e reforçar os conteúdos que estão sendo trabalhados em sala de aula, sendo assim, as tarefas de casa são uma extensão do que está sendo trabalhado”. (P2) 
V Congresso Brasileiro de Informática na Educação (CBIE 2016)

Anais do XXII Workshop de Informática na Escola (WIE 2016)

Quando questionados sobre os hábitos de estudos dos alunos no início do ano letivo, antes do uso do Moodle, os professores colocaram que de maneira geral, os estudantes não realizam regularmente as tarefas de casa.

"Os hábitos de estudos extraclasses são praticamente nulos. Os que já possuem uma rotina de estudos em casa são sempre os que realizam as tarefas propostas, devendo o professor se quiser aumentar o número de alunos realizando as tarefas de casa, desprender um esforço grande na tentativa de conscientizar alunos e família sobre a importância da continuidade dos estudos em casa e de forma regular”. (P1)

Ainda para (P2) "Antes do Moodle, a realização das tarefas era preocupante, já que no início do ano, apenas $15 \%$ dos alunos realizavam as tarefas de casa”. Para (P3) “... poucos apresentavam as tarefas de casas concluídas, com o Moodle tornou mais atrativo as atividades propostas, assim como sua relação com os conteúdos apresentados durante o ano letivo".

Os professores foram questionados quanto à percepção do impacto do Moodle no interesse pelas atividades extraclasse. Segundo eles, o interesse aumentou. O (P1) coloca que "introduzir um instrumento diferenciado ao processo de ensinoaprendizagem aumenta significativamente as chances de sucesso frente às propostas educacionais”. $\mathrm{O}(\mathrm{P} 2)$ observa que com a plataforma “... a tarefa é realizada de uma maneira diferente e mais atrativa. Percebo excelentes resultados, pois estamos falando de diferentes tecnologias digitais, portanto de novas linguagens, que devem fazer parte do cotidiano dos alunos e das escolas, o que contribui de maneira satisfatória para a aprendizagem dos alunos". Ainda, (P3) destaca: "Podemos colocar que o Moodle deixa o aprendizado mais dinâmico, os alunos podem conhecer e conviver mais de perto com vários assuntos trabalhados pelos professores nas salas de aula, hoje é necessário criar momentos em que os alunos precisam participar de outras ações, na intenção de incentivar o conhecimento com novas atividades e quebrar um pouco a rotina". Segundo (P3), após o uso do Moodle, houve maior participação também nas aulas presenciais, principalmente nas discussões, uma vez que tiveram acesso a conteúdos complementares às aulas, que contribuíram à melhor compreensão dos conteúdos.

Observou-se que integrar o Moodle às rotinas de estudo extraclasse desperta o interesse e traz motivação. Os estudantes hoje se comunicam e aprendem virtualmente, assim a tecnologia torna-lhes as atividades de estudo mais prazerosas e significativas. Os professores consideram que, de maneira geral, as atividades estão em consonância com os conteúdos propostos no currículo, uma vez que é um trabalho desenvolvido em conjunto como uma extensão das atividades desenvolvidas em sala de aula.

Em relação aos tipos de atividades (questionário, fóruns, jogos, vídeos) os professores colocam que cada uma apresenta características e objetivos diferentes contribuindo de muitas maneiras à aprendizagem. Os questionários são mais indicados para fixação do conteúdo explorado em sala. Deve-se, entretanto, evitar algumas atividades como as de perguntas e respostas por serem, de certa forma, "mecânicas" ou "tradicionais", que fazem o aluno agir tecnicamente na sua resolução, limitando a construção do conhecimento. Estas atividades são relevantes quando vinculadas a uma pesquisa direcionada. Assim, os questionários tornam-se mais interessantes se utilizam recursos como questões de associação, relação, múltipla escolha, verdadeiro ou falso, por exemplo. Um ponto positivo do recurso dos questionários segundo os professores, é 
V Congresso Brasileiro de Informática na Educação (CBIE 2016)

Anais do XXII Workshop de Informática na Escola (WIE 2016)

que as perguntas são lançadas aleatoriamente em cada uma das três tentativas que o aluno pode realizar, de forma que o aluno é estimulado a ler e pensar antes de responder.

Os vídeos são formas de agregar mais informações ao conteúdo de uma forma diferenciada. Os jogos, apesar de não terem seus resultados expressos nos relatórios dos alunos, são formas de fixação do conteúdo de maneira lúdica, interativa e motivadora. Jogos, Quiz e vídeos são recursos que estimulam as funções psicológicas superiores como atenção, percepção, memória, pensamento, linguagem e sensação.

Sobre os fóruns de discussão (P1) afirma que “... são de grande relevância pelo motivo do aluno naquele momento estar expressando sua opinião e com isto construindo conceitos e abstraindo os conteúdos trabalhados.". (P3) os considera interessantes: "... pois possibilitam que os alunos interajam entre eles.".

Ainda de acordo com a opinião dos professores, acompanhar o desempenho dos alunos nas atividades propostas no Moodle é interessante. Segundo eles o acesso e a visualização são práticos. “... facilita o trabalho, se ganha tempo para acompanhar o desenvolvimento de cada aluno, verificar os resultados e elaborar novas atividades com as intervenções necessárias. A plataforma facilita uma atividade que é inerente à função de professor - o acompanhamento do desempenho dos estudantes" (P2).

A respeito das contribuições do projeto para o processo ensino-aprendizagem, o professor (P1) afirma: "O desempenho dos alunos melhorou gradativamente com a implantação do projeto, desenvolvendo nos alunos o hábito de estudos extraclasses, antes pouco desenvolvido, provoca uma contribuição significativa ao aprendizado, pois aumenta as horas de estudos dos alunos e consequentemente melhora seu desempenho nas atividades escolares". De acordo com (P3): "Sem dúvida houve melhor desempenho e interesse na conclusão das atividades. Quando utilizada com significado e critério, a tecnologia pode contribuir para a produção do conhecimento e a melhoria do processo ensino-aprendizagem. O professor precisa buscar conhecer e estar consciente de que o uso de TICs na educação tem reflexos na sua prática docente e nos processos de aprendizagem, conduzindo à apropriação de conhecimentos".

Os professores constataram contribuições do projeto no rendimento dos alunos pela melhoria dos hábitos de estudo propiciados pelo uso do Moodle, e que em média, $70 \%$ dos alunos passaram a realizar as lições de casa. Quanto aos alunos, um dos itens que mais gostam é assistir aos vídeos, e também de ter o resultado das atividades e o retorno do professor online após a execução. Alguns pais, embora não inqueridos comentaram ver seus filhos empolgados em fazer as atividades no computador.

\section{Conclusões}

Este é um projeto amplo e trabalhoso, que exige preparar os alunos para o uso adequado do Moodle, o que leva tempo e paciência. Também para cadastrar as atividades no sistema é preciso mais tempo do que para preparar uma atividade impressa de modo convencional ou designar algumas páginas de livros para os alunos trabalharem em casa, visto que as atividades devem ser adaptadas à plataforma a fim de evitar apenas uma transposição do livro didático. $\mathrm{O}$ fato de nem todos possuírem computador em casa também é um dificultador, tendo a escola que providenciar o acesso para estes alunos.

O projeto de aplicação de atividades extraclasse online via Moodle já se tornou uma prática na escola Aloys João Mann. O uso da plataforma tem ajudado a estimular 
V Congresso Brasileiro de Informática na Educação (CBIE 2016)

Anais do XXII Workshop de Informática na Escola (WIE 2016)

hábitos de estudos, a desenvolver a autonomia além de propiciar o acesso a um sistema que os alunos poderão deparar-se em outros momentos de sua formação.

Em relação às atividades, uma vez elaboradas, permanecem no portfólio da plataforma podendo ser reutilizadas e reformuladas quando necessário. Logo, a cada atividade inserida, o portfólio é aumentado gerando um acervo de atividades.

Este projeto continua em execução e espera-se estendê-lo a turmas de $4^{\circ}$ ano. Pela experiência, acredita-se valer o investimento da escola em projetos como estes para promover formas de acesso à tecnologia e estímulo aos hábitos de estudo. Como trabalhos futuros, uma revisão sistemática para referendar uma métrica de avaliação para esse relato de experiência será realizada, bem como a formalização de um mecanismo de avaliação sistêmica e continuada por parte da comunidade escolar.

\section{Referências}

Assemany, D.; Villar, F.; Akio, L.; Rangel, L.; Spiller, L.; Dias, P. (2010) "Utilizando o Moodle no Ensino de Matemática: uma experiência na Educação Básica". In: X Encontro Nacional de Educação Matemática, Salvador - BA, jul, p. 1-11.

Brasil (1996) Ministério da Educação. Lei de Diretrizes e Bases da Educação Nacional - LDB n 9.394/96. 20 de dezembro de 1996.

Claro, M. (2009) Como instalar o Moodle passo a passo. Portal Moodle Livre. Disponível em <https://www.moodlelivre.com.br/tutoriais-e-dicas-moodle/comoinstalar-o-moodle-passo-a-passo >. Acesso em: 26 mar. 2016.

Davídov, V.; Márkova, A. (1987) "La concepción de la actividad de estudio de los escolares. In: La psicología evolutiva y pedagógica" en la URSS: Antología. URSS: Editorial Progreso, p. 316-337.

Dewey, J. (1979 ) “Democracia e Educação”. 4ª ed. São Paulo: C. E. Nacional. 416 p.

Dougiamas, M.; Taylor, P. C. (2000) "Improving the effectiveness of tools for Internetbased education", Teaching and Learning Forum 2000, Curtin University of Technology. Disponível em <https://dougiamas.com/writing/tlf2000/> Acesso em: 12 jul. 2016.

Karas, R. A. B; Santos, J. M. T. (2008) "Moodle como Ambiente de Apoio na Disciplina de Ciências, uma Experiência na Educação Básica no Estado do Paraná". 2008. Cadernos PDE, vol.1. Secretaria de Educação do Estado do Paraná, Guarapuava/PR. Disponível em: < http://goo.gl/bPObRo>. Acesso em: 11 jul. 2016.

Libâneo, J. C. (1994). "Didática”. 1ª ed. São Paulo: Cortez. 1994. 263 p.

Rodrigues, C. A.; Elia, M. F. (2013) “Atividades Extraclasses com base no Currículo Mínimo para a Língua Inglesa usando uma Rede Social" XIX Workshop de Informática na Escola (WIE 2013), Campinas, SP, p. 319-328.

Santos, N. A. T. L. (2014) "Ensino de ciências: uma experiência da utilização do Moodle no $6^{\circ}$ e $7^{\circ}$ anos do ensino fundamental de uma escola pública de Campo Grande - MS”. Diálogos Educ. R., Campo Grande, MS, jul, v.5, n.1, p. 71-84.

Tavares, K. (2009) Entrevista concedida ao projeto LingNet. Faculdade de Letras, UFRJ. Disponível em: <https://goo.gl/KjahtR> Acesso em: 11 ago.2016. 